Revista Iberoamericana, Vol. LXXIV, Núm. 224, Julio-Septiembre 2008, 777-792

\title{
MILONGA A COMPÁS DE AUSENCIAS: EL CANTOR DE TANGO ENTRE LAS VANGUARDIAS, LA RESTITUCIÓN DE LA MEMORIA HISTÓRICA Y LA INDUSTRIA CULTURAL
}

\author{
POR \\ DiAnNa C. NiebYLSKI \\ University of Illinois-Chicago
}

Tomás Eloy Martínez comienza la narración de El cantor de tango como una parodiahomenaje al cuento "El perseguidor” de Julio Cortázar. En el cuento de este último, un crítico de jazz llamado Bruno busca frustrada y obsesivamente la modalidad descriptiva o narrativa que le permita expresar la esencia del estilo y del sonido de Johnny Carter, el saxofonista del cuento cuyo nombre es una obvia referencia al famoso Charlie Parker. En la novela de Martínez, un joven académico de Nueva York también llamado Bruno decide conseguir los fondos necesarios para viajar a Buenos Aires con la expresa misión de buscar y conocer a un cantor de tango llamado Julio Martel, en quien espera encontrar la inspiración que le falta para terminar su tesis sobre los orígenes del tango. ${ }^{1}$ Publicado en 1956 , en pleno auge postvanguardista y con el triunfo de la revolución cubana como telón de fondo, "El perseguidor" puede leerse como una doble reflexión entre lo que hay de impredecible en todo artista revolucionario (i.e., original) y la imposibilidad de explicar o describir el "genio" del artista en términos críticos; también puede leerse como la imposibilidad de separar la biografía o autobiografía del arte de la historia de la crítica. Escrita entre 2001 y 2003, la novela El cantor de tango se desarrolla en momentos en que las manifestaciones tardías de la narrativa postdictatorial compiten con nuevas tendencias narrativas que no comparten la conciencia de una globalización de efectos desiguales y del fracaso de un mercado neoliberal heredado de las dictaduras. Como "El perseguidor", la novela se inicia con la búsqueda del cantor por el crítico con la finalidad de reflexionar sobre lo que distingue a los primeros o antiguos tangos que él canta, y su estilo de cantarlos, de otros espectáculos y grabaciones más acordes con el tango actual. Pero lo que comienza como un intento de "atrapar” la esencia de una modalidad artística (el jazz, el tango), en la novela de Martínez se va convirtiendo en un medio narrativo hacia búsquedas de otra índole, mientras que los distintos discursos de la novela van poniendo en movimiento proyectos de rescate que exceden los límites

1 El nombre es una obvia alusión a Carlos Gardel, pero también a Julián Martel, el escritor naturalista de La bolsa (1891), novela en que se narra el rápido ascenso de la clase media bajo la influencia de las especulaciones bursátiles y luego su desastrosa caída con la quiebra bancaria que sigue la economía "virtual". La alusión a la novela de Martel, escrita a fines del siglo xIX, tiene el efecto de servir de espejo a la situación económica actual en la Argentina de 2001, el año en que tienen lugar los acontecimientos de El cantor de tango. 
de lo puramente artístico o literario. ${ }^{2}$ En otras palabras, si bien el motivo inicial del viaje de Bruno a la Argentina pertenece exclusivamente al ámbito de la estética, el contacto del joven académico con una realidad bonaerense en estado de disolución y derrumbamiento (a causa de la hecatombe económica del 2001), hace insostenibles sus pretensiones de neutralidad política e ideológica hacia el contexto histórico-económico que dio cabida al tango y que sigue inspirando al cantor en quien él, Bruno, espera encontrar su propio medio de rescate. En sus intentos mayormente fracasados de dar con la pista del cantor, Bruno se ve obligado a reflexionar sobre la dificultad de recuperar lo olvidado o lo borrado a la fuerza por la censura no siempre letrada del poder. El recorrido que lleva a Bruno desde su interés puramente estético por los orígenes del tango hasta su toma de conciencia ética de la importancia de preservar las historias olvidadas por la historia en una Buenos Aires postdictatorial en que bibliotecas enteras se venden por kilo, es mediado y minado por la herencia cultural, social y económica de las vanguardias y postvanguardias rioplatenses -de las cuáles “El perseguidor” de Cortázar es sólo un representante.

“¿Cómo habitar un presente hecho de ruinas modernistas y vanguardistas? ¿cómo reciclar o reapropiar gestos vanguardistas de transgresión... cuando dichos gestos se han vuelto reproducibles y coleccionables?” (435). Las interrogantes corresponden a un reciente artículo sobre una novela-reciclaje del fallecido novelista chileno Juan Luis Martínez titulada La nueva novela. En él, Laura García Moreno examina el modo en que la obra del escritor chileno gira alrededor de una preocupación que podría interpretarse como preocupación de índole puramente estético-literaria, pero que en realidad es mucho más extensa, ya que el autor -en un gesto característicamente posmoderno-pone en tela de juicio tanto la significación como el valor de la cultura en general a través de sus apropiaciones paródicas. Las interrogantes que acabo de citar son en buena parte el móvil inicial de $E l$ cantor de tango, y sin embargo una lectura paralela de estas obras deja en evidencia hasta qué punto las últimas tres décadas han ido transformando el significado de estas preguntas y sus posibles respuestassmas. Mientras que la novela de Juan Luis Martínez pertenece a la narrativa postmoderna, la de Tomás Eloy Martínez se sitúa en el cruce entre la narrativa postdictatorial y la nueva o novísima narrativa, cuyas modalidades y preocupaciones son lo suficientemente diversas como para no compartir casi nada, excepto la preocupación por el rotundo fracaso del neoliberalismo heredado de las dictaduras. La sombra siempre presente del trauma ocasionado por la dictadura, y el caos creado por el fracaso de una economía de mercados globales dominados por unos pocos centros, hace imposible retomar la preocupación por la competencia transgresiva de las vanguardias, sin tomar en cuenta los

\footnotetext{
2 Cuento y novela comparten la sensación de frustración como parte de una búsqueda, tanto por parte del artista como del crítico, que parece destinada al fracaso salvo ciertos momentos privilegiados. Hay, sin embargo, una diferencia significativa entre los narradores-perseguidores. Mientras que el Bruno de Cortázar es un aficionado al jazz que valora más la abstracción crítica que la música que la provoca, el Bruno de Martínez no parece capaz de sentir una afición particular por la música, y sólo algo más que curiosidad por el baile. Al mismo tiempo, el hecho de que se siente incapaz de escribir nada coherente y su casi crónica incapacidad de comentar sobre los fenómenos que observa, lo convierten en un personaje más indiferente hacia sus circunstancias externas, aunque no menos egocéntrico.
} 
modos en que esas mismas vanguardias -sus escritores y lectores- tuvieron momentos de complicidad con las represiones político-militares que siguieron a las revoluciones estéticas y formales de la primera parte del siglo. Si bien Bruno no es lo suficientemente astuto para verbalizar las lecciones de historia cívica que va aprendiendo a través de su búsqueda del cantante, es al menos lo suficientemente transparente como guía como para dejarle entrever al lector lo que otro narrador, con más agudeza, hubiera recogido de la experiencia.

La hibridez genérica y discursiva de esta novela hace aún más relevante-aunque más problemática- su insistencia en defender el derecho de un patrimonio cultural a rehusar convertirse en producto de atracción turística o en material de apropiación académicointelectual. El patrimonio cultural aparece en la novela bajo signos correspondientes a dos vanguardias: una de ellas concreta pero anclada a una baldosa-aleph escondida en un oscuro y sucio sótano de una pensión de mala muerte; la otra, más tenue pero no menos misteriosa, se deja escuchar en los compases de antiguos tangos entonados por la voz del cantor que insiste en rescatar una tradición oral a punto de perderse. Si bien Martínez toma el cuento de Cortázar como punto de partida, la novela está anclada insistente y obsesivamente a metáforas y a mitologías urbanas correspondientes a otros dos escritores asociados con dos de las vanguardias que más marcaron la historia artística y cultural argentina. La primera de estas figuras es Borges, aunque no el Borges de su primer ultraísmo criollista sino el Borges metafantástico de "El aleph” y de las geometrías urbanas de "La muerte y la brújula. La segunda es Roberto Arlt, no a través de un personaje o un texto particular sino reflejado en las figuras incongruentes -cotidianas y a la vez expresionistas- que componen el ambiente de arrabal alucinado de la pensión en que reside el protagonista y el fracaso entre biológico (hereditario) y económico que caracteriza a los años de formación del cantor. Aunque desprovisto de las ansias de venganza de los memorables malevos de Arlt, también el cantor termina tramando sus propios actos de revancha histórica ante la acumulación de tantas miserias. ${ }^{3}$

UN “ALEPH” PARA EL RECUERDO, O LA IMPOSIBILIDAD DE HABITAR EL PRESENTE

A mí también me había costado delatar. Y sin embargo, el aleph me había importado más que la indignidad. (153)

En Evaristo Carriego y en El tamaño de mi esperanza, Borges descubre la singularidad de un vocabulario y unos arquetipos correspondientes a los comienzos del tango. Aunque Borges luego reniega de estas obras tempranas, los arquetipos de este mundo del hampa tanguera seguirán traicionándose y acuchillándose en sus cuentos, encontrando en ellos más larga vida y mayor difusión que en las muchas novelas realistas o naturalistas de la misma época ahora olvidadas. En lo concerniente a la obra de Borges, los primeros experimentos vanguardistas corresponden a una labor de archivo, aunque el archivo en este caso fueron las calles y cafetines de Palermo. Para fines de la década de 1920, cuando

3 No faltan otros ecos y otras alusiones literarias: a Adán Buenosayres (novela en la que el tango tiene un papel clave); a las novelas de Ricardo Piglia en la proliferación de historias dentro de la historia (aunque Piglia, como ha notado Avelar, es decididamente antibiográfico). 
Borges vuelve a Buenos Aires, tanto la imagen del tango como la del cantor de tango está cambiando rápidamente, animada, sin duda, por la contribución de tantos compositores inmigrantes (cuya influencia Borges lamenta y declara culpable de la corrupción del tango). Sus ensayos, en los que busca demostrar la superioridad y mayor autenticidad del tango de la primera etapa, esos que, en palabras de Bruno, “se habían compuesto antes de 1910, cuando aún se bailaban en los burdeles, y no los que aparecieron después, influidos por el gusto de París y por las tarantelas genovesas” (15). Erigiéndose como guardián de un vocabulario que se va perdiendo, el autor de El tamaño de mi esperanza recoge mucho de este vocabulario criollista, gesto del que pronto se averguenza y arrepiente, y por el que no permite la reimpresión del texto. Con la creciente fama, el escritor se irá distanciando cada vez más de sus primeras creaciones. Por su parte, críticos y lectores pronto dejan de lado al Borges de la primera vanguardia.

El camino que lleva a Borges a alejarse del mundo quizás demasiado físico y pasional del tango en busca de los laberintos más fríos de la metafísica es repetido en la novela por Bruno. Habiendo venido a Buenos Aires a buscar material del "primer” Borges sobre los orígenes del tango, Bruno decide, aún antes de salir del aeropuerto, rehacer su itinerario seducido por la idea de alquilar un cuarto en una pensión de la calle Garay, donde, según el Tucumano, un personaje que trabaja algunas horas en el aeropuerto, hay un aleph (pronunciado "alé" por el tucumano que ignora la fuente de la alusión). Prueba contundente de la existencia de dicho objeto para el Tucumano es el hecho de que una compañía de turismo trae a grupos de turistas extranjeros a ver el sótano donde está el aleph una vez por mes. Si bien Bruno no desiste en ningún momento de su búsqueda del cantor, su progresiva obsesión por apropiarse del aleph lo llevará a querer desalojar al viejo bibliotecario que vive en el sótano para quedarse él mismo en posesión de un objeto en cuya realidad no termina de creer. El creciente interés de Bruno por la herencia de la vanguardia borgiana más rentable (la que sí logró trascender el interés de la crítica nacional para convertirse en el emblema más conocido y más citado de la postmodernidad) lo lleva a descuidar sus lecturas en la Biblioteca Nacional y a perder interés en la tesis que vino a completar. De esa manera la "traición” al patrimonio nacional cometida por Borges al ir del tango a los "juegos con el infinito” es repetida por Bruno, quien pierde interés en la obra de Borges sobre el tango al dejarse seducir por la posible presencia del aleph en el sótano de su pensión. De esta manera, el gesto que traiciona la herencia nacional en nombre de un patrimonio más exportable anticipa las otras traiciones que la novela va revelando: la del público cada vez menor hacia el cantor cuyos tangos se vuelven cada vez más incomprensibles, la del país hacia las jóvenes mujeres que vinieron engañadas por compadritos que se hicieron ricos con la trata de blancas en las décadas de la inmigración masiva a Buenos Aires, la de la dictadura hacia seres brutalizados y desaparecidos, la de las políticas neoliberales iniciadas por las dictaduras hacia la clase media, la cual en la novela termina viviendo (o muriendo) en una villa miseria al no lograr rescatar sus ahorros ni mantener sus puestos de trabajo. ${ }^{4}$

4 Como Carlos Argentino Daneri, Bonorino busca recoger lo que va aprendiendo del aleph en una "enciclopedia patria." Mientras que como lectores sabemos que los esfuerzos de Bonorino serán en vano, lo que no es vano es la guardia del bibliotecario ante el precioso objeto, ya que sólo esta guardia casi permanente, y el papeleo que va cubriendo la baldosa protege el objeto de una 
"Trapped between the imperative of memory and a general inability to imagine an alternative future, postdictatiorial fiction maintains an estranged, denaturalized relation with its present” (10). La observación de Idelber Avelar sobre el tratamiento de la temporalidad en varias narrativas postdictatoriales muy distintas de la Martínez coincide, sin embargo, con el modo en que El cantor de tango niega la posibilidad de habitar el presente a aquellos que buscan rescatar o afirmar la necesidad de mantener vivos ciertos momentos del pasado. Bruno, quien cambia de opinión varias veces sobre la posible realidad o autenticidad del aleph, decide después intentar desalojar a Bonorino del sótano, que este último no puede tener el aleph. El poseedor del aleph, nota Bruno, conocería la existencia de la carta traicionera escrita por Bruno y por lo tanto no le pediría que guarde los cuadernos dedicados a registrar lo que el bibliotecario ha visto en el aleph. Si recordamos que en el aleph del joven Borges había la infinita multiplicidad del presente desde todos las perspectivas posibles, ${ }^{5}$ en el aleph del sótano ocupado por Bonorino, lo que el bibliotecario dice haber visto, mayormente, es el pasado (sólo más tarde sabemos que también ha visto ciertos destellos de su propio futuro. De modo que o no se trata del mismo aleph, o la función principal del aleph se ha transformado para ajustarse a las necesidades del presente. En un momento en que la tecnología, con su infinitud de redes telefónicas y telescópicas, hace posible el "universo de la Pantopia” (Serres, 122) y en un país que ha borrado episodios enteros de un pasado difícil, el aleph de la calle Garay sirve ahora, no para magnificar infinitamente la experiencia del momento presente sino para restituir momentos del pasado. Como el historiador del ensayo de Walter Benjamin, Bonorino ve las pérdidas que se van acumulando en las calles y barrios de Buenos Aires (entre otras, la pérdida de Estela Canto, que inspira a Borges a vengarse de la intrusa que lo deja con un amor no correspondido, escribiendo un cuento sobre su muerte). Las imágenes llenas de ausencia que recoge Bonorino a través de sus "tomas" del pasado urbano en el aleph sirven de contrapunto a las voces e historias de seres desalojados a quien busca honrar el cantante durante los últimos días de su vida. Entre esta ciudad colmada de ausentes y un futuro que aún no alcanza a distinguir, Bruno parece moverse casi inconcientemente en un presente que no acaba de habitar.

Por la fecha en que comienza la narración, deducimos que Bruno llega a Buenos Aires poco antes o poco después del ataque a las torres gemelas. Una frase añadida a la traducción en inglés aclara que el viaje de Bruno tiene lugar dos semanas antes del ataque a las torres. Es imposible, por lo tanto, que Bruno no esté plenamente conciente de las consecuencias inmediatas del evento sobre amigos y conocidos que viven en la ciudad que él dejó justo antes de la catástrofe. El hecho de que sea incapaz de mencionarlo es prueba de que el personaje está tan traumatizado por el evento que es incapaz de procesarlo. Por otra parte, Bruno es apenas capaz de procesar la catástrofe económica que está viviendo Buenos

explotación turística mucho más ofensiva y dañina de la que hay. Al ver sólo papeles cubriendo los últimos escalones, los turistas piensan que la parada de "el alé" es una patraña de la agencia de turismo y se van sin intentar bajar hasta el primer escalón.

5 "Lo que vieron mis ojos fue simultáneo, lo que transcribiré, sucesivo, porque el lenguaje lo es... Al principio la creí giratoria; luego comprendí que ese movimiento era una ilusión producida por los vertiginosos espectáculos que encerraba. Cada cosa (la luna del espejo, digamos,) era infinitas cosas, porque yo claramente la veía desde todos los puntos del universo” (“El aleph”). 
Aires -y toda Argentina- entre los meses de septiembre y diciembre de 2001. Vistas desde este ángulo, la búsqueda del cantor, búsqueda que había dado las claves necesarias para terminar su proyecto de tesis y así dar fin a una etapa de su vida que él describe como una especie de limbo al comienzo de la novela, se convierte en una forma de escapismo. Para Bonorino y para Martel, la necesidad de rescatar el pasado (a través del aleph, a través de las ceremonias que honran a los que desparecieron o fueron brutalizados por la historia) es todo lo contrario de una forma de escapismo. Para quienes han vivido y sufrido las catástrofes de la historia en carne propia, la única esperanza de dar sentido al presente es registrar y recordar el pasado sin falsearlo en el acto de rescatarlo.

Mientras Bonorino busca rescatar la topografía urbana de una ciudad desaparecida con el fin de reduplicarla en una "enciclopedia patria", Julio Martel, el cantor epónimo, dedica los últimos meses de su existencia a honrar a un puñado de "desaparecidos” y desconocidos de la historia con su voz en actos públicos que terminan siendo mayormente privados -e irreproducibles. En la selección de textos que él escoge para indagar sobre las características del discurso. Mucho antes de convertirse en un cantor cuyo fin es la restitución de los olvidados y maltratados por la historia, sin embargo, el joven que elige llamarse Julio Martel sueña con convertirse en compadrito.

EL CANTOR: DEPOSITARIO DE VIEJOS TANGOS, COMPADRITO MANQUÉ, PORTAVOZ DE LOS OLVIDADOS ${ }^{6}$

El menos compadrito de todos los representantes literarios del elenco de cantores de tango empieza queriendo ser otro Gardel. Stefano Caccace (alias Julián Martel), padece de una hemofilia que lo deja casi paralítico antes de cumplir los treinta años. Es puro torso sobre unas piernas inútiles que apenas puede mover con la ayuda de un bastón. Lo que tiene en cambio es una voz imborrable para quienes la escuchan, una voz capaz de tornar viva la historia narrada por las letras del tango. Describiendo el primero y último concurso al que se presenta el cantor basándose en un artículo que encuentra en una revista sobre la biografía del cantor, Bruno lo describe con una admiración y una emoción que parece incapaz de sentir cuando se encuentra en presencia de otras personas (incluso del mismo cantor hacia el final de la novela):

Tal vez sus ademanes fueran una parodia de los que se veían en las películas del cantor inmortal. Pero la voz era única. Alzaba vuelo por su cuenta, desplegando entera y, por supuesto, más de los que dejaba entrever, con modestia, el tango de Celedonio Flores. "Mano a mano” evocaba la historia de una mujer que abandonaba al hombre que amaba por una vida de riquezas y placer. Martel lo convertía en un lamento místico sobre la carne perecedera y la soledad del alma sin Dios. (37)

El romanticismo nostálgico de la descripción puede justificarse, tal vez, como el intento de Bruno por repetir el juicio del periodista en el artículo -aunque de todas maneras suena

6 Un posible modelo para el cantor de Martínez podría ser Luis Cardei, cantante de enorme talento, oriundo de Villa Urquiza y aficionado al Hipódromo. Otros posibles modelos podrían ser Raúl Berón o Ángel Vargas. Lo que tiene en común Cardei con el cantante de la novela de Martínez es la predilección por tangos práctimente olvidados y rara vez ejecutados. 
discordante con otros pronunciamientos más neutros por parte del narrador. El aura que sustenta la descripción no es compartida para nada por Martel, quien se apasiona desde muy pequeño por las letras de los tangos más antiguos y por la figura de Gardel, pero con fines estrictamente veniales. Los primeros le interesan porque es capaz de apreciar el ingenio de la frase o la gracia de la expresión y porque, con su memoria fotográfica, se sabe capaz de rescatarlos del olvido; lo segundo porque, como todo joven de su generación, ve en Gardel un modelo de éxito (en la sociedad, con las mujeres), inalcanzable a través de otra profesión. Incapaz de triunfar en los grandes salones, o aún en los clubes populares en parte por su propia vergüenza ante su falta de atractivo físico y en parte por su insistencia en incorporar a su recital tangos que casi nadie entiende (por el lunfardo anticuado de la letra), Martel se ve obligado a ganarse la vida primero memorizando las fichas de las quinielas en el cuarto de atrás de una funeraria y luego -gracias a su memoria prodigiosa- asegurarse de que ganase la casa en los juegos de póker organizados en la sala de atrás de la misma funeraria, y usando los ataúdes como mesas de juego. Una inspección a la funeraria durante la dictadura militar termina en un juicio que deja libre al propietario pero causa el encarcelamiento de Martel, quien es sentenciado a pasar seis meses en una cárcel.

En un reportaje-entrevista con Susana Rosano, Tomás Eloy Martínez alude al comentario de Beatriz Sarlo sobre el aspecto morboso de su novela Santa Evita notando que "en Argentina todos caemos en el barroco fúnebre...” (660). El espacio de la funeraria donde el cantor trabaja durante años en la sala de atrás, memorizando los naipes y los números que salen para que gane "la casa," sirve de puente entre la primera parte de su vida y sus últimos años. Después de su experiencia en la cárcel por haber trabajado en el negocio ilegal de la funeraria, el cantor es un hombre cambiado. De sus primeros años sabemos que se comportaba, cuando podía, como un aprendiz de compadrito -Alcira es testigo de su antigua reputación de mujeriego. Es después de su experiencia en la cárcel durante la década de los setenta que descubre su nuevo destino. Poco a poco va dejando de cantar en clubes y se limita a dar recitales improvisados en lugares de la ciudad sobre los que sólo él (y sus pocos acolitos) entiende el significado.

Dada la insistencia de la novela en recoger y salvaguardar momentos y escenarios de las vanguardias argentinas de comienzos del siglo xx, el modo en que el magnífico pero malhadado cantor se gana la vida en una funeraria contrasta fuertemente con algunos de los espectáculos del "barroco fúnebre” de ciertos “espectáculos” vanguardistas de comienzos de siglo (aunque no de Borges). Entre ellos, el espectáculo de Oliverio Girondo paseándose por las calles de la capital en un coche fúnebre alquilado, con su esposa Norah Lange vestida de vampiresa, sentada en un ataúd abierto y repartiendo anuncios para el nuevo libro de poesía de Girondo, Espantapájaros. ${ }^{7}$ Cuando el cantor, salido de la cárcel, se decida a improvisar espectáculos públicos, sus brevísimas apariciones por la ciudad tendrán un propósito totalmente opuesto al del espectáculo de Oliverio. Mientras que el conocido poeta vanguardista (quien además era un señorito de la vieja alcurnia) buscaba el modo de "épater le bourgeois" creando un barroco morboso a partir de un escenario funerario para promocionar su libro, Martel reservará al final de su vida la poca voz que le queda para

\footnotetext{
7 Agradezco a Patrick O’Connor la información sobre este episodio.
} 
cantar ante nadie (o casi nadie) en un acto fúnebre tan privado como minimalista, acto resistente a la publicidad y a la comercialización.

Si en lo concerniente al mundo de la pensión que alquila Bruno, la vanguardia dominante (o el emblema vanguardista dominante) es la del Borges de "El aleph" la historia de Martel tiene toques indiscutibles de otra vanguardia: el expresionismo hiperrealista de Roberto Arlt. Los detalles más macabros de la vida de Martel -su nacimiento, sus enfermedades, combinados con la rareza o la singularidad del personaje- son altamente sugerentes de los ambientes arltianos. El lugar donde el cantor canta durante más tiempo es una librería cuyo nombre, "El Rufián Melancólico", alude a uno de los personajes más famosos de Arlt. Como la herencia de Borges a través del aleph de la pensión, la herencia de Arlt se rescata con diferencias. Ni Martel ni los pocos amigos que forman su elenco sienten sed de vengarse de sus circunstancias, o de aquellos que los victimizaron. La restitución, no el desquite, es el gesto en que culmina la vida del cantor.

EL CANTOR II: ¿ “EL BARROCO FÚNEBRE” O EL DUELO MINIMALISTA?

\begin{abstract}
La gente desaparecía por millares durante aquellos años y el cantor también se desdibujó en la rutina de la funeraria, donde trabajaba setenta horas por semana. Como las quinielas habían sido legalizadas, el dueño las sustituyó por mesas de póker y bacarat instaladas al fondo del local, sobre los ataúdes sin uso. Martel tenía el don de saber qué cartas saldrían en cada ronda, e indicaba a los empleados, por un sistema de gestos, cómo tenían que jugar. Acudían numerosos técnicos y obreros sin empleo, y en cada una de las mesas había tanta tensión, tanto deseo de domesticar a la suerte, que Martel sentía remordimiento por acentuar la ruina de aquellos desesperados. (39)

No se puede decir nada, inmediatamente lo traduces a tu sucio idioma. Si cuando yo toco tú ves a los ángeles, no es culpa mía. Si los otros abren la boca y dicen que he alcanzado la perfección, no es culpa mía. Y esto es lo peor, lo que verdaderamente te has olvidado de decir en tu libro, Bruno... (Johnny a Bruno, en "El perseguidor")
\end{abstract}

Tomas Eloy Martínez ha notado en varias entrevistas de periódicos que la novela recoge, con detalles ficticios pero en un gesto de homenaje, una suma de crímenes cometidos con impunidad en la ciudad de Buenos Aires. Mayormente narradas por Alcira -la compañera de Julio Martel- y recogidas por Bruno, las minihistorias dentro de la novela dan un itinerario y una explicación al mapa urbano que el cantor va trazando a través de la novela y que Bruno - atrapado dentro del paradigma metaficticcional del Borges de "El aleph"- es incapaz de descifrar a pesar de sus ingeniosos intentos. Una vez que Alcira va armando el rompecabezas, sin embargo, el itinerario urbano del cantor resulta ser una especie de via crucis para evocar la memoria de aquellos para quienes ningún Borges escribirá un cuento, ni siquiera con la intención de vengarse. De ese modo, un Martel ya muy enfermo canta en el Palacio de las 
Aguas, donde hace más de un siglo se descubrió el cadáver de una niña ahorcada por una venganza que nada tenía que ver con ella sino con un odiado policía de la zona; canta frente al Club Atlético, honda reflexión sobre las razones que mueven a crear arte, su verdadero significado y la multiplicidad de interpretaciones, entre las que no es necesariamente más verdadera la del propio artista que la del crítico que falsea datos o la del observador casual donde cientos de personas fueron torturadas y asesinadas por los militares; canta en frente a una sinagoga bombardeada en 1994, asesinando a ochenta y cuatro personas; canta donde una joven polaca fue asesinada por la policía militar al ser acusada de ayudar a esconder a su amante guerrillero. Es para rendir homenaje a todos ellos que durante los últimos años de su vida el cantor se va convirtiendo en la voz que busca recordar y rescatar las historias de aquellos muertos a destiempo o injustamente.

Las obras The Art of Transition de Francine Masiello, Residuos y metáforas de Nelly Richard y The Untimely Present, el libro ya citado de Idelber Avelar, examinan las tendencias más frecuentes de la narrativa postdictatorial. Entre ellas destacan la tensión entre el documento oficial y la ceremonia privada como medios para rescatar el pasado, así como la elaboración de una nueva conceptualización de la noción de fracaso. ${ }^{8}$ Estos estudios coinciden, además, en notar que una de las características más frecuentes de la narrativa postdictatorial es la fragmentación y la dificultad estructural y formal del texto. Según estos críticos, la arbitrariedad y las rupturas de la narración no hacen sino reflejar la imposibilidad de rescatar lo que se busca recordar de manera lineal o fácilmente accesible. De acuerdo a este criterio, la novela de Martínez no entraría en el marco de narrativas valoradas como postdictatoriales. Su estructura, a pesar de contener múltiples líneas narrativas, no presenta dificultades formales o estilísticas. Por otra parte, las diversas historias dentro de la historia no se entremezclan como en La ciudad ausente de Ricardo Piglia.

La novela de Martínez parece resistir la seducción del orden (y del relato lineal) en lo que concierne a la historia del narrador (cuya propia historia queda al margen de la novela) pero se rinde a dicha seducción a través de los relatos de Alcira, la musa que interpreta para Bruno los movimientos. Con una excepción, los relatos narrados por Alcira tienen una facilidad de expresión y una carga nostálgica que las excluye de la narrativa postdictatorial -aunque las inserta dentro del género “[c]omo el testimonio histórico radica en la autenticidad, aquel también es puesto en peligro por la reproducción cuando la duración sustantiva deja de importar” (220). testimonial de años anteriores. La facilidad con que Alcira logra encapsular estas historias en un vocabulario accesible y un estilo que no denota alteraciones de ningún tipo nos hace cuestionar su autenticidad aún sabiendo que están basadas en eventos históricos. Lo cuestionable no es la historia, sino la modalidad narrativa en que se recoge y narra.

Según Nelly Richard, lo que hace menos verosímiles ciertas narraciones testimoniales es precisamente la facilidad con que se narran. Para Richard, el desorden semiótico-sintáctico que acompaña la experiencia del trauma asociado con la violación o la brutalización es una de las marcas de autenticidad de la memoria del torturado o brutalizado. Es cierto que

\footnotetext{
8 A esta lista deberían agregarse los últimos trabajos de Moreiras, especialmente The Exhaustion of Difference, con la provisión de que para Moreiras la expresión estética o artística en sí es de mucho menor interés que la crítica cultural de la estética.
} 
Alcira misma no es víctima de la violencia política y social registrada en las historias, pero la facilidad con que las recoge para beneficio de Bruno tiene el efecto de contrarrestar, hasta cierto punto, los gestos improvisados y fragmentados del cantor con el fin de rendir homenaje a estos hombres y mujeres sin resumir su historia en un relato nostálgico. Mientras que el gesto del cantor -inútil como símbolo de una cultura masmediática-resulta convincente con el telón de fondo de un país en las garras del fracaso neoliberal. Por el contrario, la elección de una narrativa lineal y casi sin huecos que necesiten llenarse con palabras o silencios de aquellos que ya no pueden contar su propia historia, establece una seria discordancia con el propósito del cantor. Sólo aquellos textos que ignoran la naturaleza del duelo, concluye Avelar refiriéndose a la narrativa en general, o que lo reprimen, pueden seguir narrando como si hoy en día se pudiera narrar sin confrontar "la intraducibilidad de la experiencia” (20).

En The Art of Transition, Francine Masiello avanza la tesis de que es en los textos postdictatoriales escritos por mujeres donde la fragmentación y la experimentación son más notables. Al usar como modelo de su Alcira-Scheherezade un modelo de musa más acorde a las narraciones más falogocéntricas del boom que a la narrativa postdictatorial de autoras como Luisa Valenzuela, Diamela Eltit, Tununa Mercado, o Liliana Heker, El cantor de tango opta por un término medio entre la incomprensibilidad o la incomunicabilidad de las experiencias de las vidas de otros que busca honrar, fugitivamente y a viva voce y el sueño de un orden narrativo utópico que recoja y documente dichas experiencias. Por su parte, al añadir a algunas de estas historias su propia postdata, con frecuencia de carácter totalizador o asimilativo, Bruno contribuye al engaño del que es víctima Alcira, aunque nunca el cantor. ${ }^{9}$

Por su parte, y aunque mucho más comprometida con el pueblo y con su causa que Bruno, Alcira está tan empeñada en rescatar la narración (la historia) de las historias que relata, que termina ignorando y convirtiendo las ausencias que deberían dejar huecos y paréntesis en dichos relatos en presencias retóricas, de modo que en vez de participar en el duelo al que nos convoca el cantor volvemos a condenar a los olvidados a la dominación del orden, ahora del orden sintáctico. De modo que en vez de hablar con el fantasma, las minihistorias sólo logran hablar del fantasma.

El único relato narrado por Alcira -y resumido o ampliado por Bruno- que no obedece el patrón de un a sintaxis accesible que caracteriza al resto de sus anécdotas, es el correspondiente a la historia del Mocho, el amigo de la infancia de Martel. El desorden se debe, sin duda, a que Alcira recuerda sólo fragmentos del relato, o a que es incapaz de rearmar el rompecabezas que un Mocho muerto de sueño y aún alucinado por la irrealidad de sus propias experiencias intenta contarle a Martel antes de desaparecer del todo. No es coincidencia, sin embargo, que sea ésta la más impactante de las historias narradas por Alcira. La historia Mocho, joven que crece en la pobreza, como Martel, y como Martel con un notable defecto físico (el horror de una voz que es un ronquido), es la historia del robo del cadáver de Aramburu. La evidente verosimilitud de la historia de Mocho radica,

\footnotetext{
9 Ver, por ejemplo, la conclusión de Bruno ante el final del relato de Felicitas Alcántara, donde el protagonista llega a la conclusión de que entre Felicitas y Evita hay un puente erigido por la envidia y la misoginia nacional.
} 
en mi opinión, en dos elementos que Alcira, al confundirse o no recordar bien los datos de la historia, no logra disimular al narrarla: el primero es la sensación del absurdo kafkiano que cuelga sobre la capital en la época de la dictadura; el segundo es la sensación de que la historia está llena de fantasmas. ${ }^{10}$

En una entrevista concedida en Santiago de Chile en 1995 con motivo de la publicación de su libro Espectros de Marx, Jacques Derrida recuerda a sus interlocutores la estrecha conexión entre el teatro (el espectáculo) y el espectro:

\begin{abstract}
El concepto de espectro irradia por sí mismo una intensidad escénica, es inmediatamente teatral. Habla y hace hablar a todo el mundo, nos ventrilocua, igual que respiramos. No sólo a causa de la referencia a Shakespeare, al teatro dentro del teatro de Hamlet, sino porque todo el espacio teatral parece pertenecer a la espectralidad. Depende de su lógica, lo mismo que los personajes, los actores y sus voces, que son a la vez visibles e invisibles, aquí y allá, allá y en otra parte, apareciendo y desapareciendo en su aparición misma, encarnados y descarnados, presentes con una presencia que no es la suya, una presencia a la vez sensible e insensible, incorpórea y corpórea, etc.
\end{abstract}

La íntima relación entre espectáculo y espectro señalada por Derrida parece escapársele a Bruno, quien es incapaz de medir la importancia capital de lo espectral en la vida del cantor, ni siquiera con la ayuda de Alcira. Como las imágenes que Bonorino presencia en el aleph, los relatos a través de los que Alcira intenta explicarle a Bruno las actuaciones itinerantes del cantor durante los meses en que Bruno ha intentado perseguirlo por la ciudad, dejan en evidencia que es en el ámbito de lo espectral donde yace buena parte de la realidad urbana de la Buenos Aires a la que ha venido Bruno. La ciudad está llena de fantasmas, pero Bruno parece no darse cuenta de ello.

ENCUENTROS Y DESENCUENTROS

\begin{abstract}
Me senté en el vestíbulo del hotel, vencido. No había encontrado nada de lo que fui a buscar en Buenos Aires, $y$ ahora además me sentía ajeno a la ciudad, ajeno al mundo, ajeno a mí. En lo que estaba sucediendo fuera se adivinaba un alumbramiento, un principio de la historia -o un fin-, y yo no lo entendía, yo sólo pensaba en la voz de Martel que jamás había oído y que tal vez nunca oiría. (217)

Durantemuchos años, en libros ahora felizmenteolvidados, traté de redactar el sabor, la esencia de los barrios extremos de Buenos Aires... no prescindí de palabras como cuchilleros, milonga, tapia, y otras, y escribí así aquellos olvidables y olvidados libros... luego... escribí una historia que se llama "La muerte y la brújula" que es una suerte de pesadilla... en que figuran elementos de Buenos Aires
\end{abstract}

\footnotetext{
${ }^{10}$ No llegué a leer La pasión y la excepción, el magnífico estudio de Beatriz Sarlo, hasta después de escrito este artículo. De haberlo leído antes hubiera tenido algunas hipótesis más sobre la conexión entre el Borges de Evaristo Carriego y el mundo del hampa y la muerte de Aramburu.
} 
deformados por el horror de la pesadilla... publicada esa historia, mis amigos me dijeron que al fin habían encontrado en lo que yo escribía el sabor de las afueras de Buenos Aires. Precisamente porque no me había propuesto encontrar ese sabor, porque me había abandonado al sueño, pude lograr, al cabo de tantos años, lo que antes busqué en vano. (Borges, Obras completas I: 270-1)

En la novela Errante en la sombra de Federico Andahazi, publicada también en 2004, un descendiente de inmigrantes gallegos nacido en un conventillo de la Boca resulta tener un talento comparable al de Gardel, de quien termina siendo chofer. Una tercera novela publicada pocos meses antes que estas dos, El bailarín de tango de Juan Terranova (2003), donde se nota fuertemente la influencia y el gusto de Manuel Puig por el diálogo y el chisme, confirma la resurgencia o reapropiación del tango de parte de escritores argentinos que sin duda presenciaron con sospecha y resignación las múltiples y muy exitosas expropiaciones del tango por cineastas y directores de comedias musicales extranjeros durante las últimas dos décadas, y del tango como salvación o posible salvación de los que de otro modo hubieran pasado del todo desapercibidos, con el contexto urbano de Buenos Aires como telón de fondo. ${ }^{11}$ Mucho menos multifacéticas que la de Martínez, ni la novela de Andahazi ni la de Terranova intentan un gesto de restitución histórica. Lo que sí tienen en común -aunque no todas logran comunicarlo convincentemente- es la inquietud por buscar en el tango algo parecido a la alegoría de una esencia netamente argentina.

Según la tesis de Marta Savigliano en Tango and the Political Economy of Passion, publicado en 1995, la inmensa popularidad internacional del tango refleja la fascinación del occidente con lo exótico: para la autora, el tango sirve como alegoría de una pasión marcada por la prohibición y el peligro asociado con lo otro. Centrada principalmente en el baile y en el espectáculo bailado del tango, Savigliano ve en la coreografía del tango un código en el que se van definiendo el papel de la raza y el sexo en las relaciones sociales nacionales. De este modo, dice la autora, el tango va hilvanando la historia de una pasión cuidadosamente coreografiada en la que se explicita el juego de poder, sexo y mercado. La exportación del tango desde el espacio colonizado hacia el centro colonizador, intuye Savigliano, está signada por el estigma asociado con el deseo del otro, de lo otro, por el otro. Explicando luego la reapropiación del tango por los mismos argentinos, después de que la música y el baile son apropiados por Paris y Japón, la autora nota la tentación, difícilmente resistida, del escritor o músico nacional que ahora decide transformar el "capital exótico" del tango en producto nacional una vez más. El argumento de Savigliano -más complejo

11 En 2005 aparece también la multifacética obra Angora Matta: Fatal Acts of North-South Translation, de la antropóloga y crítica cultural argentina radicada en Estados Unidos, Marta Savigliano, cuya parte central es una opera u opereta con música de tango. Sin embargo, lo que quiero notar en este primer párrafo no es sólo la coincidencia de estas tres novelas de autores argentinos centradas sobre el fenómeno del tango, sino el hecho de que al menos dos de ellas se centren en la figura de un cantor de voz sobrehumana y de un talento quizás superior al más mítico de los cantantes, que por circunstancias diversas y por ser provenientes de la clase obrera, viven marginados y terminan olvidados. 
de lo que sugiere mi corto resumen aquí- podría resultar convincente a la hora de explicar la persistente fascinación con el tango no sólo en la música argentina sino en la literatura argentina a lo largo del siglo. ${ }^{12}$

Martínez parece compartir el deseo nostálgico del escritor exiliado, trasplantado o de algún otro modo marginado, de anclar una novela cuyo género se debate entre la biografía ficcionalizada y el testimonio, al símbolo más conocido y evidentemente traducible de su país. Como noté anteriormente, sin embargo, la casi total ausencia de espectáculo y de pasión o posesión sexual asociados con el mundo de malevos y compadritos hace que la novela se convierta más en una crítica de la búsqueda de la identidad que en la posibilidad de llevar a buen fin dicha búsqueda. Es más, al centrarse en un cantor cuyo repertorio incluye principalmente tangos que casi nadie conoce y pocos logran entender (por tratarse del lunfardo cerrado de comienzos de siglo), Martínez se sirve del tango no como alegoría nacional sino como aporía que sostiene y a la vez desestabiliza la noción de una identidad histórico-étnico-cultural argentina que se debate entre lo auténtico y la imitación; entre la tradición autóctona y la novedad; entre el olvido institucionalizado que amenaza con arrasar en limpio con el pasado, y los actos conmemorativos a través de los cuales el cantor intenta honrar a los olvidados y desaparecidos de algunas tragedias nacionales olvidadas o desconocidas. Mediando este diálogo y por encima de él, se encuentran los fantasmas más ilustres -y más perdurables- de las vanguardias bonaerenses que a comienzos del siglo xx compitieron a rabiar por la atención del público y de la crítica nacional. Aunque hay inconsistencias en el tratamiento de Martínez en su apropiación de las herencias de estas dos vanguardias, el intento de mediatizarlas y hacerlas dialogar refleja la necesidad de establecer puentes entre el cosmopolitismo (elitista) del Borges que abandona demasiado

${ }^{12}$ En la década de los años veinte y treinta del siglo xx aparecen no sólo los escritos de Borges al respecto. Son estos escritos que el narrador de Martínez supuestamente viene a estudiar. La presencia del tango está también en las novelas del otro vanguardista argentino, Roberto Arlt, cuya desafortunada (y errónea) identificación con el grupo de Boedo resultó en una marginalización y falta de apreciación crítica de su original mezcla de expresionismo y neorrealismo. A pesar de haber pocas referencias tangueras en Arlt, es imposible separar a algunos de sus personajes más memorables de su afición por el tango. Tanto el Rengo en El juguete rabioso como el Rufián Melancólico en Los lanzallamas son inseparables de los tangos que tararean o recuerdan mientras sueñan o ponen en acción sus nefastos planes para vengarse de alguien, o para triunfar sobre el monstruo de la sociedad que los condenó a la derrota desde su nacimiento. Más tarde, en los años cuarenta y cincuenta, el tango seguirá figurando como un personaje principal en la literatura de la "retaguardia” del neorrealismo: Adán Buenosayres de Leopoldo Marechal, “Toribio Torres, alias Gardelito” de Bernardo Kordon y Calles de tango de Bernardo Verbitsky, entre los más conocidos. Cortázar sólo tiene comentarios irónicos y despectivos hacia los aficionados del tango en su primera novela, Los premios. Sin embargo, en 1980, basándose en algunas anécdotas sobre el fin incierto de la prostituta favorita de Toulouse-Lautrec y la última (e inacabada) obra del pintor sobre ella, $L a$ maison de la Rue des Moulins, Cortázar escribe Un gotán para Lautrec, un ensayo ficcionalizado en el cual especula sobre lo que le ocurre a Mireille después de haberse ido a Buenos Aires animada por las promesas de los hermanos Villanueva, comerciantes en la trata de blancas. La obra es, como el título lo anuncia, un homenaje al tango -en particular los tangos de los años treinta. También en la década de los ochenta Manuel Puig vuelve al tango al combinar parodia y nostalgia en Boquitas pintadas. 
pronto su interés en lo nacional o criollista, y el localismo alucinado de un expresionista hiperbólico pero comprometido con la hibridez de una población cada día más mixta.

En su reciente obra The Exhaustion of Difference, Alberto Moreiras retoma un concepto que tanto Nelly Richard como Idelber Avelar identifican con la narrativa postdictatorial. Todo proyecto cultural o intelectual latinoamericano contemporáneo, nota Moreiras, está marcado por la huella de lo residual; por aquello que resiste la reducción de una realidad compleja a cualquier sistema o explicación totalizante o sintética. La tesis de Moreiras, quien en general no se ocupa de demostrar la aplicación de ciertos conceptos a la producción estética, significa un giro nuevo para las políticas identitarias de los estudios culturales de diez años atrás, cuando animaban a los sujetos minoritarios o étnicos a identificarse con los rasgos predominantes de su género, raza, etnia, clase o nacionalidad con fines políticos o ideológicos. ${ }^{13}$

En la ya referida entrevista con Susana Rosano, Tomás Eloy Martínez comenta que su última novela, El cantor de tango, comenzó como un proyecto por encargo a pedido de la editorial Bloomsbury en octubre del año 2000. Lo que Bloomsbury le había pedido era una crónica de la ciudad de Buenos Aires para una serie titulada "Los escritores y sus ciudades”. Martínez nota en dicha entrevista, sin embargo, que el interés del editor surgió a raíz de un sueño que él le había relatado. En el sueño, Martínez trataba de encontrar a un cantor de tango inimitable, sin lograrlo. La premisa del proyecto, según el autor, fue desde el comienzo una premisa novelística, no ensayística. Lo que nunca llega a completarse como crónica ensayística, se convierte en cambio en novela. El cantor de tango aparece primero en traducción al inglés publicada por la editorial Bloomsbury en 2004, y casi inmediatamente en una edición en español publicada por Planeta. Es posible ver en lo residual, o en los desencuentros o desajustes de la novela, los inicios multigenéricos del proyecto original.

Tratándose de una novela que afirma lo irreductible del residuo, la elección del autor de cerrarla con un gesto circular no deja de ser inesperada y discordante. El contrapunteo que se establece a través de la novela entre la actitud del crítico que viene en busca de una identidad original y originaria, y el cantor que termina sus días improvisando ceremonias de rescate, termina con el regreso del narrador al teclado, supuestamente para escribir la novela que acabamos de leer. La mención de otro cantor de tango a quien el narrador debiera conocer, abre la posibilidad de que todo se repita una vez más (aludiendo otra vez al eterno retorno nietzscheano como la contrapartida a la acumulación de despojos benjaminiana), pero el gesto que le permite al narrador volver a su manuscrito para terminarlo es un gesto demasiado afirmativo para no contrastar fuertemente con la problemática de la representación histórica que la novela ha puesto en tela de juicio a través de sus más de doscientas páginas. Es un final demasiado eficaz para una novela que logra convencernos de la imposibilidad de cerrar cómodamente el capítulo correspondiente al trauma de la dictadura, o buscarle una salida fácil a la tragedia de otros episodios penosos de la historia argentina. Si las vanguardias rescatadas por la novela han logrado ser tan duraderas es precisamente por haber sabido que la historia -a diferencia de los mitos- no tiene un cierre definitivo y

${ }^{13}$ Véase Richard, “Insertando latinoamérica con el latinoamericanismo: discurso académico y crítica cultural”. 
catártico. De haber aprendido la lección que la historia de su peregrinaje-persecución le tenía reservada, Bruno debería haber llegado a la misma conclusión. ${ }^{14}$

\section{BiBLIOGRAFÍA}

Andahazi, Federico. Errante en la sombra. Buenos Aires: Alfaguara Argentina, 2004.

Avelar, Idelber. The Untimely Present. Postdictatorial Latin American Fiction and the Task of Mourning. Durham: Duke UP, 1999.

Borges, Jorge Luis. El tamaño de mi esperanza. Buenos Aires: Alianza, 1926. Evaristo Carriego. Buenos Aires: Gleizer Ed., 1930.

Derrida, Jacques. “Entrevista con Nadine Eghels”. Espectografías. Julio D. Díaz y Carolina Meloni, trad. (desde Marx y Derrida) Cristina de Peretti, ed. (Madrid, 2003) <http:// www.jacquesderrida.com.ar/textos/marx_alguien.htm>

Franco, Jean. The Decline and Fall of the Lettered City. Latin America in the Cold War. Cambridge: Harvard UP, 2002.

García Moreno, Laura. "El texto en ruinas: la política del reciclaje en La nueva novela de Juan Luis Martínez”. Revista Iberoamericana LXXII/215-216 (abril-septiembre 2006): 433-48.

Martínez, Tomás Eloy. El cantor de tango. Buenos Aires: Planeta, 2004.

The Tango Singer. Anne McLean, trad. Nueva York: Bloomsbury Publishing, 2004.

Masiello, Francine. The Art of Transition: Latin American Culture and Neoliberal Crisis. Durham: Duke UP, 2001.

Moreiras, Alberto. The Exhaustion of Difference. The Politics of Latin American Cultural Studies. Durham: Duke UP, 2001.

Piglia, Ricardo. La ciudad ausente Buenos Aires: Sudamericana, 1992.

_ 1990.

Richard, Nelly. Residuos y metáforas: ensayos de crítica cultural sobre el Chile de la transición. Santiago: Cuarto Propio, 1998.

"Insersectando Latinoamérica con el latinoamericanismo: discurso académico y crítica cultural”. <http://www.ensayistas.org/ critica/ teoria/ castro/richard.htm> y Francesca Lombardo y Diamela Eltit. "Lo que brilla por su ausencia.” Revista de crítica cultural 11 (nov. 1995): 28-43.

Rosano, Susana. "En definitiva, en Argentina todos caemos en el barroco fúnebre. Reportaje a Tomás Eloy Martínez”. Revista Iberoamericana LXXVII/215-216 (abril-septiembre 2006): 657-62.

Sarlo, Beatriz. La pasión y la excepción. Buenos Aires. Siglo XXI Editories, s.a. 2003.

Savigliano, Marta. Tango and the Political Economy of Passion. Boulder: Westview Press, 1995.

${ }^{14}$ Agradezco al Profesor Patrick O’Connor, y a Steven Buttes y Emilio Sauri, alumnos de posgrado de la Universidad de Illinois, Chicago, por sus inteligentes sugerencias sobre una versión temprana de este artículo. 
Angora Matta: Fatal Acts of North-South Translation/Actos Fatales de traducción norte-sur. Westview Press, 2003.

Serres, Michel. Atlas. Madrid: Cátedra, 1995.

Terranova, Juan. El bailarín de tango. Buenos Aires: Ediciones Deldragón, 2003. 